RESEARCH

\title{
Anti-tumour activity of everolimus and sunitinib in neuroendocrine neoplasms
}

\author{
Kosmas Daskalakis ${ }^{1,2}$, Marina Tsoli ${ }^{2}$, Anna Angelousi ${ }^{2}$, Evanthia Kassi ${ }^{2,3}$, Krystallenia I Alexandraki $^{2}$, \\ Denise Kolomodi ${ }^{2}$, Gregory Kaltsas ${ }^{2,4,5 *}$ and Anna Koumarianou ${ }^{6 *}$ \\ ${ }^{1}$ Department of Surgical Sciences, Uppsala University, Uppsala, Sweden \\ ${ }^{21} 1$ st Department of Propaupaedic Internal Medicine, Endocrine Unit, Laiko Hospital, National and Kapodistrian University of Athens, Athens, Greece \\ ${ }^{3}$ Department of Biological Chemistry, Medical School, National and Kapodistrian University of Athens, Athens, Greece \\ ${ }^{4}$ Clinical Sciences Research Laboratories, Warwick Medical School, University of Warwick, University Hospital, Coventry, UK \\ ${ }^{5}$ Centre of Applied Biological \& Exercise Sciences, Faculty of Health \& Life Sciences, Coventry University, Coventry, UK \\ ${ }^{6}$ Haematology-Oncology Unit, Fourth Department of Internal Medicine, Attikon University General Hospital, National and Kapodistrian University of \\ Athens, Athens, Greece
}

Correspondence should be addressed to G Kaltsas: gkaltsas@endo.gr

*(G Kaltsas and A Koumarianou contributed equally)

\begin{abstract}
Comparisons between everolimus and sunitinib regarding their efficacy and safety in neuroendocrine neoplasms (NENs) are scarce. We retrospectively analysed the clinicopathological characteristics and outcomes in 92 patients with well-differentiated (WD) NEN of different origin (57 pancreatic NENs (PanNENs)), treated with molecular targeted therapy (MTT) with everolimus or sunitinib, first- (73:19) or second-line (sequential; 12:22) for progressive disease. Disease control rates (DCR: partial response or stable disease) at first-line were higher in all patients treated with everolimus than sunitinib (64/73 vs $12 / 19, P=0.012$ ). In PanNENs, DCR at first-line everolimus was 36/42 versus $9 / 15$ with sunitinib $(P=0.062)$. Progression-free survival $(P F S)$ at first-line everolimus was longer than sunitinib ( 31 months ( $95 \%$ Cl: $23.1-38.9)$ vs 9 months ( $95 \% \mathrm{Cl}$ : $0-18.5)$; $\log$-rank $P<0.0001$ ) in the whole cohort and the subset of PanNENs (log-rank $P<0.0001$ ). Median PFS at second-line MTT was 12 months with everolimus (95\% Cl: 4.1-19.9) vs 13 months with sunitinib (95\% Cl: 9.3-16.7; log-rank $P=0.951)$. Treatment with sunitinib (HR: 3.47; 95\% Cl: 1.5-8.3; $P$ value: 0.005$), \mathrm{KI} 67>20 \%$ (HR: 6.38; 95\% Cl: $1.3-31.3 ; P=0.022$ ) and prior chemotherapy (HR: $2.71 ; 95 \% \mathrm{Cl}: 1.2-6.3 ; P=0.021$ ) were negative predictors for PFS at first line in multivariable and also confirmed at multi-state modelling analyses. Side effect (SE) analysis indicated events of serious toxicities (Grades 3 and 4: $n=13 / 85$ for everolimus and $n=4 / 41$ for sunitinib). Discontinuation rate due to SEs was 20/85 for everolimus versus $4 / 41$ for sunitinib $(P=0.065)$. No additive toxicity of second-line MTT was confirmed. Based on these findings, and until reliable predictors of response become available, everolimus may be preferable to sunitinib when initiating MTT in progressive NENs.
\end{abstract}

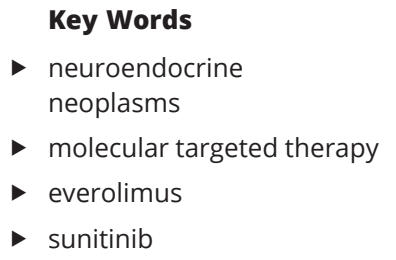

Endocrine Connections (2019) 8, 641-653

\section{Introduction}

Neuroendocrine neoplasms (NENs) represent a heterogeneous group of tumours with variable clinical behaviour and unpredictable prognosis. Their incidence has increased substantially in recent years, partly due to the development of accurate pathologic and diagnostic tests, but also because of the increased awareness of these tumours by clinicians (1). NEN biology has also been clarified to some extent, paving the way for the https://ec.bioscientifica.com https://doi.org/10.1530/EC-19-0134 (c) 2019 The authors Published by Bioscientifica Ltd
This work is licensed under a Creative Commons Attribution-NonCommercial-NoDerivatives 4.0 elnternationab ticense.ifica.com at 04/26/2023 12:33:49PM 
development of novel molecular targeted therapies (MTTs). MTTs with the MTOR inhibitor everolimus and the receptor tyrosine kinase (RTK) inhibitor sunitinib have been approved in clinical practice for locally advanced and metastatic pancreatic NENs (PanNENs) $(2,3)$. In addition, everolimus has been shown to exhibit activity in NENs originating from other tissues in phase III studies, whereas phase II studies have shown that RTK inhibitors could also be used in particular clinical settings in such NENs (4, 5 , 6). However, one of the main challenges regarding the effective treatment of NENs with these agents is related to the paucity of validated biomarkers to select the best candidates for MTT and monitor side effects (SEs), survival outcomes and responses.

In particular, the serine/threonine kinase mammalian target of rapamycin (MTOR) signalling pathway plays a pivotal role in the regulation of cell proliferation and metabolism, survival, motility and autophagy. Its activation has been associated with a poor prognosis and high proliferation index (KI67) $(7,8)$. Everolimus interacts with the MTOR pathway and related intracellular pathways, suppressing downstream multi-protein complexes and increasing progression-free survival (PFS) across different sets of NENs $(9,10,6,3)$. On the other hand, angiogenesis in NENs is of paramount importance, though not yet fully explained (11). A large placebo-controlled phase III trial has demonstrated that sunitinib, which is a potent multitargeted RTK inhibitor of VEGFR1-3, PDGFR-A, PDGFR-B and C-KIT, resulted in a PFS improvement in patients with metastatic pancreatic NENs (PanNENs) (2).

Small series on sequential use of MTT in PanNENs has demonstrated similar PFS and tolerability for everolimus and sunitinib at first- and second-line MTT (12). However, head-to-head comparison of MTT efficacy and toxicity is rather limited; randomized trials are lacking, whereas there are only few small retrospective studies in PanNENs available, comparing everolimus with sunitinib $(12,13)$. Importantly, MTTs with everolimus and sunitinib have distinct SE profiles, which differ from those of cytotoxic chemotherapies. The continual and occasionally prolonged nature of orally administered MTT leads to new challenges in their application and the management of potential additive toxicity when used sequentially.

The objectives of this study were to assess the antitumour activity of MTT with everolimus or sunitinib administered alone or sequentially, in terms of the impact of each drug in DCR and PFS and also to explore their SE profiles and potential additive toxicity, by means of collecting real-world data.

\section{Subjects and methods}

Ninety-two consecutive patients with inoperable Stage IIIb and Stage IV NENs who received MTT with everolimus or sunitinib, alone or sequentially, from 1 May 2008, to 30 September 2018, were identified from a single tertiary NEN referral centre in Athens, Greece. Patients' files were chosen on the basis of a centrally reviewed biopsyproven, advanced or metastatic well-differentiated (WD) NEN. Up until September 2018, patients were discussed at multidisciplinary meetings and, for MTT initiation, patients had to have disease progression as documented by Response Evaluation Criteria in Solid Tumors (RECIST) (14). Patients were selected for MTT initiation with either everolimus or sunitinib after central assessment of crosssectional imaging. The selection of first-line MTT therapy was based on international guidelines, but also on the presence of comorbidities, patient's performance status and preference. Hence, despite similar clinical presentation, everolimus has been offered as first-line treatment in some patients, whereas sunitinib has been offered to others. First-line MTT was administered to patients who experienced disease progression during watchful waiting or treatment with either somatostatin analogues (SSAs) or chemotherapy. Second-line (sequential) MTT with sunitinib or everolimus was administered in a subset of NEN patients after disease progression or serious toxicity while on first-line MTT with everolimus or sunitinib, respectively. Importantly, since neither everolimus nor sunitinib was officially licensed for the treatment of nonpancreatic NENs before 2016, off-label administration of MTT to such patients required approval from the hospital ethical/scientific committee and also the pertinent national regulatory authority. Preliminary data in a subset of 19 patients who received sequential MTT had previously been published (12). Data on histopathology, grading and secretory status, functional imaging properties (fluorodeoxyglucose positron emission tomography (FDGPET) and somatostatin receptor imaging (Octreoscan or ${ }^{68} \mathrm{Ga}$-DOTATOC PET)), as well as prior lines of treatment including surgery, were retrospectively collected.

Tumour-cell differentiation and KI67 labelling index (LI) were determined from primary site, lymph node or liver biopsies. Centrally, we retrospectively reassessed all the available tumour tissues according to the 2000 and evolved 2017 WHO classification system for grading. Additionally, the stage of all patients was centrally re-evaluated based on the 8th edition of the American Joint Committee on Cancer (AJCC) classification for 
TNM staging $(15,16)$. Other clinicopathologic variables recorded at data entry (MTT initiation) included age, sex, genetic predisposition/family history, primary tumour site, secretory status, liver tumour load, somatostatin receptor positivity on octreoscan or ${ }^{68} \mathrm{Ga}$-PET/CT, FDG-PET/CT avidity, concomitant use of SSAs, previous treatments and the Charlson Comorbidity Index. The Charlson Comorbidity Index is a validated scale for survival (higher scores indicate more comorbidities) (17). Subsequently, all patients with NEN primaries were categorized into three groups according to the KI67 LI at the time of MTT initiation: Group 1: KI67 <3\%, Group 2: KI67 3-20\% and Group 3: KI67 > 20\%.

Duration of MTT administration, reason to stop treatment and MTT SE data were also extracted from patient records. SEs were graded using the National Cancer Institute Common Terminology Criteria for Adverse Events CTCAE v 5.0 (18). Disease progression was assessed according to the Response Evaluation Criteria in Solid Tumours (RECIST version 1.1) (14).

The study was approved by the Regional Ethics Review Board in Athens, Greece. Written informed consent was obtained from all study participants. To ensure the quality of data reporting, we followed the STROBE statement (19).

\section{Statistics}

All analyses were done using the SPSS 23.0 software package (IBM SPSS Statistics, Armonk, NY, USA) and R (version 3.2.4; R Foundation for Statistical Computing, Vienna, Austria). To avoid immortal time bias, baseline for overall survival (OS) and PFS analyses was defined as the first date for MTT. Preliminary analyses included estimation of the chi-square test and the Kaplan-Meier survival curves for PFS and OS, stratified by a number of baseline variables and the log-rank testing of the differences in survival between the respective strata for patients receiving first-line and sequential second-line MTT, respectively. Patients still receiving MTT without exhibiting progression entered the analysis with PFS equal to the duration of treatment. Patients were censored at the time they were lost to follow-up or at the end of the study, in September 2018. Multivariable Cox regression PFS analysis was employed to assess prognostic factors at treatment initiation for first-line MTT. Additionally, we employed the multi-state Markov piecewise constant intensities model (MKVPCI) to assess hazard ratios (HR) with confidence intervals (CI) at first- and second-line MTT and to validate the results of the Cox regression analysis. MKVPCI not only generalizes the single-endpoint survival

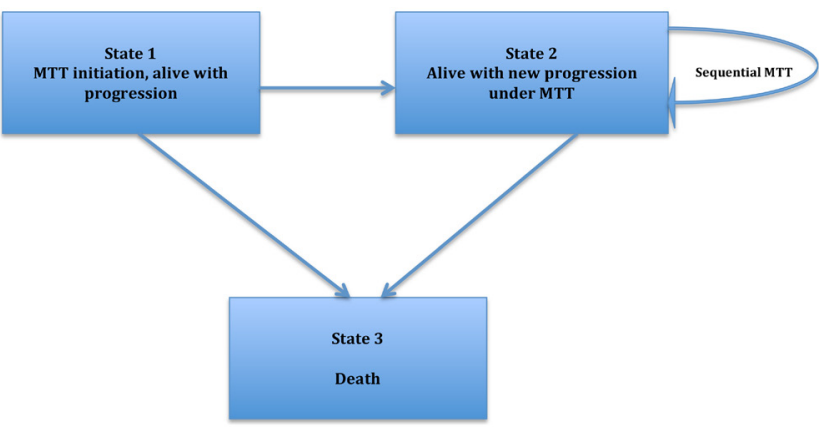

\section{Figure 1}

Markov multi-state model of cancer progression and mortality. Three possible states are considered: (1) MTT initiation, alive with progression, (2) alive with new progression under MTT and (3) death.

analytical models, such as Cox's model, but also allows for simultaneous estimation of the effects of prognostic factors on the hazard of transitions between all clinically relevant health states of interest and avoids potentially important biases due to non-random censoring $(20,21)$. We modelled transitions between three states: (A) MTT initiation, alive with progression at Stage IIIb or IV; (B) alive with new progression under MTT and (C) death (Fig. 1). The MKVPCI model allowed us to estimate the separate effects of each prognostic factor: (i) new progression after first-line MTT (transition (A-B)); (ii) new progression after second-line MTT (B-B) and (iii) death after progression (B-C). In the estimation process, it was assumed that all cohort members were initially at risk of either transition (A-B) or transition (A-C), until the time of their progression (state B), death (state $\mathrm{C}$ ) or censoring at the end of follow-up (if they remained in state A). Finally, shrinkage for control of confounders was applied between primary recorded variables and derived outcomes in different patient states during the study period for the MKVPCI model (22). With the aim of eliminating validity threats to stepwise analysis, shrinkage methods applied here allowed us to address residual confounding by entering each covariate in the model, along with prior data that limit the size of the residual effects, e.g. when a subset of patients switched from everolimus to sunitinib and vice versa (22).

\section{Results}

\section{Patient characteristics}

Ninety-two consecutive patients (34 females; mean age \pm S.D. at MTT initiation: $58 \pm 14$ years) with progressive inoperable locally advanced $(n=8)$ or metastatic $(n=84)$ well-differentiated (WD) NENs were included in the

This work is licensed under a Creative Commons Attribution-NonCommercial-NoDerivatives 4.0 Internationab kicense.ifica com at $04 / 26 / 2023 \quad 12: 33: 49 \mathrm{PM}$ 
analysis. Figure 2 presents the study flow. Patient and tumour characteristics are summarized in Table 1. A firstline MTT with everolimus or sunitinib was administered in all 92 patients (everolimus, $n=73$; sunitinib, $n=19$ ). A second-line (sequential) MTT was administered in 34 patients: in particular, 22 patients received first-line everolimus followed by sunitinib, and 12 were assigned to first-line sunitinib followed by everolimus. Of the 92 patients included in the study, 74 had sporadic tumours and 8 familial NENs in the context of multiple endocrine neoplasia type 1 (MEN 1) syndrome. Based on primary tumour location, cases were grouped into small intestinal NENs $(n=21)$, pancreatic NENs (PanNENs) $(n=57)$, lung/ thymic NENs $(n=7)$ and unknown primary origin NENs (UPO-NENs, $n=7$ ). Thirty-four patients had a functioning tumour. Fifteen patients had KI67 <3\%; 63 had KI67 $3-20 \%$ and six had KI67 $>20 \%$ (range of KI67 in these six cases: $25-70 \%)$. In the remaining eight patients, the grade was unknown.

Surgery with the intention to cure or control hormonal symptoms was performed on 52 patients prior to MTT. First-line MTT was administered after progression while on SSAs or just observation in 65 patients. Firstline MTT constituting subsequent lines of treatment after disease progression with other chemotherapy was administered in 27 patients. Somatostatin analogues (SSAs) were co-administered in 86/92 patients at firstline and 33/34 patients at second-line MTT, respectively. For patients receiving sequential MTT $(n=34)$, the time interval $(m e a n \pm$ s.D. $)$ between the first-and the

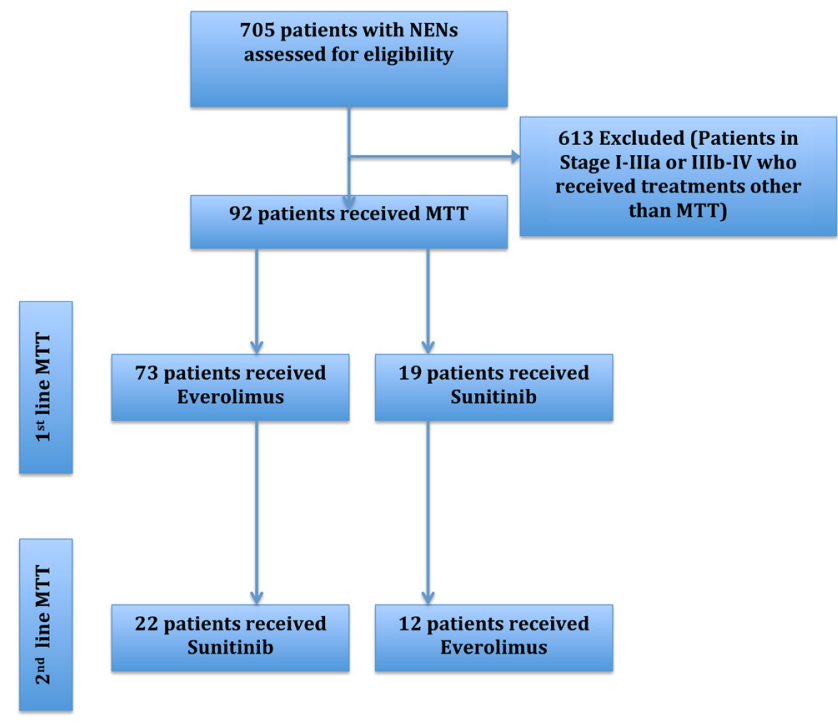

Figure 2

Study flow diagram. MTT, molecular targeted therapy; NENs, neuroendocrine neoplasms.

https://ec.bioscientifica.com https://doi.org/10.1530/EC-19-0134 Published by Bioscientifica Ltd second-line treatment was $3.5 \pm 5.4$ months. Additionally, in this subset, the time interval did not differ significantly in either the everolimus to sunitinib group or the sunitinib to everolimus group $(P=0.151)$.

The majority of patients had somatostatin receptor imaging (Octreoscan, Tektrotyd or ${ }^{68} \mathrm{Ga}$-DOTATOC PET) performed prior to MTT initiation, showing a positive uptake in 74 cases. ${ }^{18} \mathrm{FDG}$-PET was performed in a subset of 25 patients, of whom 12 had a positive uptake.

\section{Duration of treatment}

Median duration of first-line MTT for the entire cohort was 16.5 months (range 1-89). For everolimus, median duration of first-line MTT was 21 months (range 1-89) and 6 months (range 1-27) for sunitinib. Median duration of second-line MTT was 10 months (range 1-77) for the entire cohort: 10 months (range 3-77) for everolimus and 9.5 months (range 1-59) for sunitinib.

\section{Anti-tumoural activity}

Disease control rate $(\mathrm{DCR}=$ partial response $(\mathrm{PR})+$ stable disease (SD)) during MTT administration was documented according to RECIST criteria at any time after MTT initiation. DCRs with respect to patient and tumour characteristics are presented in Table 2 for first-line MTT and in Supplementary Table 2 (see section on supplementary data given at the end of this article) for second-line MTT. DCR was higher in patients receiving everolimus than sunitinib at first-line MTT (DCR: 64/73 (8PR-56SD) vs 12/19 (1PR-11SD); $P=0.012$; Table 2). In patients with PanNEN ( $n=57)$, DCR at first-line MTT was $36 / 42$ with everolimus vs $9 / 15$ with sunitinib $(P=0.062$; Table 2$)$. In the subgroup analysis of data from first-line MTT, DCR was higher in the everolimus group than the sunitinib group in patients with KI67 $3-20 \%$ (45/48 vs $10 / 15$; $P=0.039$; Table 2) and advanced LTL ( $>10$ or diffuse liver metastases; $42 / 49$ vs $10 / 16 ; P=0.029$; Table 2 ). The DCR of second-line MTT did not differ significantly between patients receiving everolimus vs sunitinib (DCR: 8/12 (1PR-7SD) vs 17/22 (OPR-17SD), $P=0.687$; Supplementary Table 1). Accordingly, in the subset of PanNEN patients who received second-line MTT $(n=28)$, DCR was $7 / 10$ with everolimus vs $13 / 17$ with sunitinib $(P=0.782$; Supplementary Table 1). With regards to subgroup analysis for second-line MTT, no associations were evident between DCR and other potentially predictive parameters presented in Supplementary Table 1. With respect to DCR, separate analysis was undertaken in the subset of
This work is licensed under a Creative Commons Attribution-NonCommercial-NoDerivatives 4.0 Internationab sicense.ifica . com at 04/26/2023 12:33:49PM 
Table 1 Patient characteristics at MTT initiation.

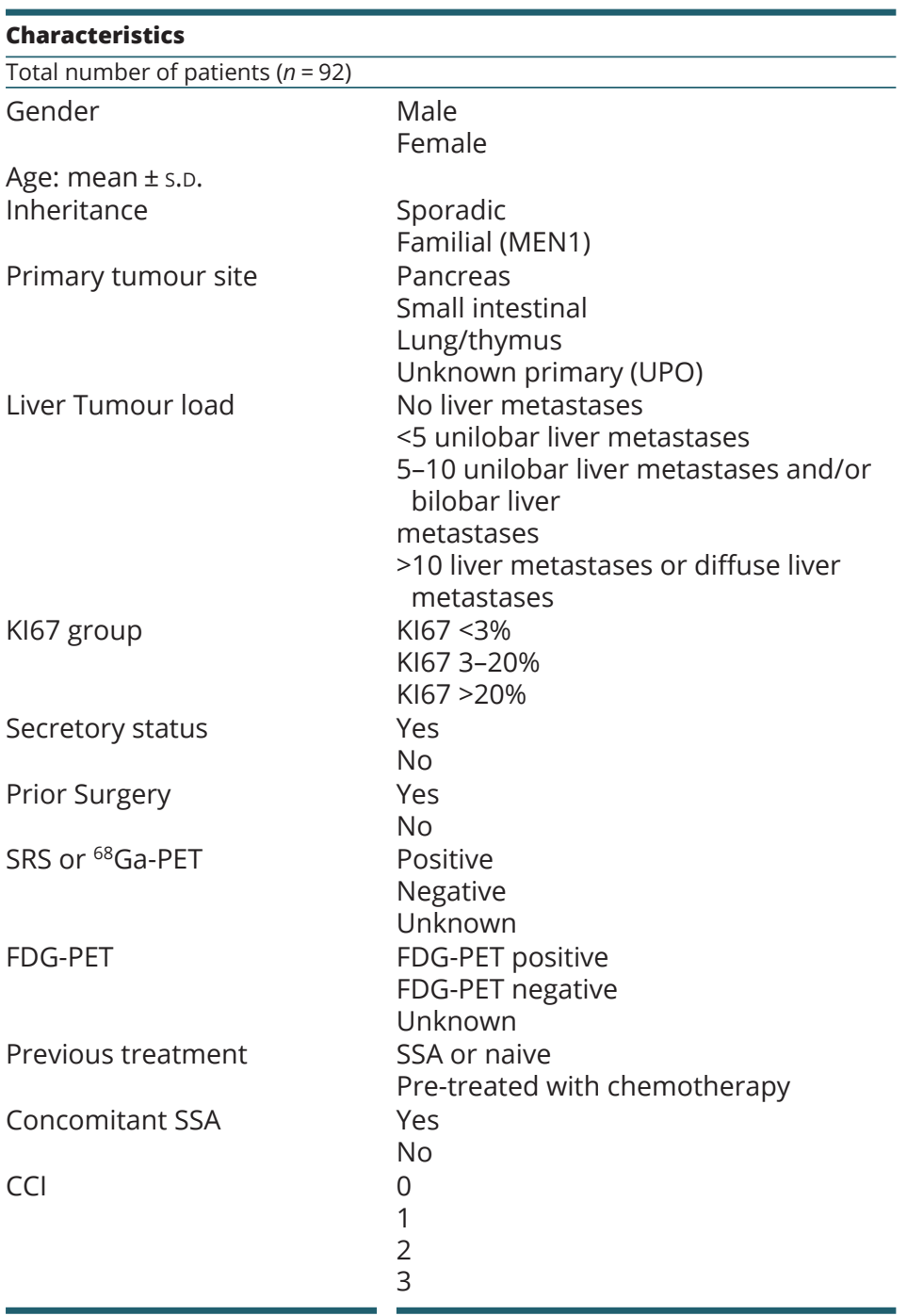

\begin{tabular}{c}
\hline Everolimus group \\
\hline No of patients $(n=73)$ \\
\hline 46 \\
27 \\
$58 \pm 14$ \\
67 \\
6 \\
42 \\
19 \\
7 \\
5 \\
7 \\
11 \\
6 \\
49
\end{tabular}

\begin{tabular}{ccc}
\hline Sunitinib group & & \\
\cline { 1 - 1 } \cline { 1 - 1 } No of patients $(n=19)$ & & 0.991 \\
12 & & \\
7 & & \\
$56 \pm 15$ & & 0.680 \\
17 & & 0.751 \\
2 & \\
15 & \\
2 & \\
0 & \\
2 & \\
1 & 0.188 \\
1 &
\end{tabular}

Pearson chi-square test and Fisher's exact test were conducted as appropriate.

CCl, Charlson Comorbidity Index; FDG-PET, fluoro-deoxyglucose positron emission tomography; Ga, Gallium; MEN1, multiple endocrine neoplasia type 1; MTT, molecular targeted therapy; SSA, somatostatin analogue; SRS, somatostatin receptor scintigraphy.

PanNENs, as presented in Supplementary Tables 2 and 3. As stratification by the KI67 proliferation index was linked with higher DCR to first-line everolimus in tumours with KI67 of 3-20\%, we performed a receiver-operator curve (ROC) analysis to identify non-responders (progressive disease (PD) recorded only) in the whole cohort and in the subset of PanNENs. However, KI67 failed to predict treatment response in these ROC analyses $(\mathrm{AUC}=0.57$ in NEN and AUC $=0.443$ in PanNENs; Supplementary Figs 1 and 2).

Functional imaging properties with respect to SRS and ${ }^{18}$ FDG-PET avidity did not correlate with DCR in any subgroup (comparison: everolimus vs sunitinib; Table 2 and Supplementary Table 1).

\section{Survival analysis of clinico-pathological prognostic factors at baseline}

Median PFS to first-line MTT was 31 months (95\% CI: 23.1-38.9) in the everolimus group versus 9 months (95\% CI: 0-18.5) in the sunitinib group, respectively (logrank $P<0.0001$; Fig. 3). Median PFS to second-line MTT was 12 months (95\% CI: 4.1-19.9) in the everolimus group versus 13 months (95\% CI: 9.3-16.7) in the sunitinib group, respectively (log-rank $P=0.951$; Supplementary Fig. 1). On multivariable Cox regression PFS analysis at first-line MTT, the selection of sunitinib (HR: 3.47; 95\% CI: $1.5-8.3 ; \quad P=0.005$ ), KI67 >20\% (HR: 6.38; 95\% CI: $1.3-31.3 ; P=0.022$ ) and prior administration 
Table 2 Disease control rates (partial response or stable disease) according to RECIST during first-line MTT.

\begin{tabular}{|c|c|c|c|c|}
\hline \multicolumn{2}{|c|}{ Patient characteristics $(n=92)$} & DCR in everolimus group & DCR in sunitinib group & \multirow{2}{*}{$\begin{array}{c}\text { P value } \\
0.012\end{array}$} \\
\hline & & $n=64 / 73$ & $n=12 / 19$ & \\
\hline \multirow[t]{2}{*}{ Gender } & Male & $41 / 46$ & $9 / 12$ & 0.342 \\
\hline & Female & $23 / 27$ & $3 / 7$ & 0.061 \\
\hline \multirow{2}{*}{\multicolumn{2}{|c|}{$\begin{array}{l}\text { Age: mean } \pm \text { S.D. } \\
\text { Inheritance }\end{array}$}} & $58 \pm 13.6$ & $61 \pm 15.4$ & 0.549 \\
\hline & Sporadic & $59 / 67$ & $11 / 17$ & 0.069 \\
\hline Inheritance & Familial (MEN1) & $5 / 6$ & $1 / 2$ & 0.464 \\
\hline \multirow[t]{4}{*}{ Primary tumour site } & Pancreas & $36 / 42$ & $9 / 15$ & 0.062 \\
\hline & Small intestinal & $18 / 19$ & $1 / 2$ & 0.271 \\
\hline & Lung/thymus & $6 / 7$ & $0 / 0$ & - \\
\hline & Unknown primary (UPO) & $4 / 5$ & $2 / 2$ & 0.999 \\
\hline \multirow[t]{4}{*}{ Liver Tumour load } & No liver metastases & $6 / 7$ & $1 / 1$ & 0.999 \\
\hline & $<5$ unilobar liver metastases & $10 / 11$ & $1 / 1$ & 0.999 \\
\hline & 5-10 unilobar liver metastases and/or & $6 / 6$ & $1 / 1$ & - \\
\hline & $\begin{array}{l}\text { bilobar liver metastases } \\
\text { >10 liver metastases or diffuse liver } \\
\text { metastases }\end{array}$ & $42 / 49$ & $9 / 16$ & 0.039 \\
\hline \multirow[t]{3}{*}{ KI67 Group } & $\mathrm{G} 1(\mathrm{KI} 67<3 \%)$ & $11 / 13$ & $2 / 2$ & 0.999 \\
\hline & G2 (KI67 3-20\%) & $45 / 48$ & $10 / 15$ & 0.029 \\
\hline & G3 (KI67 > 20\%) & $2 / 5$ & $0 / 1$ & 0.999 \\
\hline \multirow[t]{2}{*}{ Secretory status } & Yes & $27 / 29$ & $4 / 5$ & 0.488 \\
\hline & No & $37 / 44$ & $8 / 14$ & 0.062 \\
\hline \multirow[t]{2}{*}{ Prior surgery } & Yes & $37 / 40$ & $8 / 12$ & 0.072 \\
\hline & No & $27 / 33$ & $4 / 7$ & 0.316 \\
\hline \multirow[t]{3}{*}{ SRS or ${ }^{68} \mathrm{Ga}-\mathrm{PET}$} & Positive & $53 / 60$ & $9 / 14$ & 0.062 \\
\hline & Negative & $6 / 6$ & $3 / 3$ & - \\
\hline & Unknown & $5 / 7$ & $0 / 2$ & 0.167 \\
\hline \multirow[t]{3}{*}{ FDG-PET } & FDG-PET positive & $5 / 8$ & $2 / 4$ & 0.231 \\
\hline & FDG-PET negative & $10 / 10$ & $2 / 3$ & 0.999 \\
\hline & Unknown & $49 / 55$ & $8 / 2$ & 0.099 \\
\hline \multirow[t]{2}{*}{ Previous treatment } & SSA or naive & $52 / 56$ & $6 / 9$ & 0.073 \\
\hline & Pre-treated with chemotherapy & $12 / 17$ & $6 / 10$ & 0.683 \\
\hline \multirow[t]{4}{*}{$\mathrm{CCl}$} & 0 & $45 / 52$ & $9 / 13$ & 0.237 \\
\hline & 1 & $13 / 14$ & $3 / 6$ & 0.061 \\
\hline & 2 & $5 / 6$ & $0 / 0$ & - \\
\hline & 3 & $1 / 1$ & $0 / 0$ & - \\
\hline
\end{tabular}

Pearson chi-square test and Fisher's exact test were conducted within subgroups as appropriate. Bold indicates statistical significance.

$\mathrm{CCl}$, Charlson Comorbidity Index; Cl, confidence interval; FDG-PET: fluoro-deoxyglucose positron emission tomography; Ga, Gallium; HR, hazard ratio; MEN1, multiple endocrine neoplasia type 1; MTT, molecular targeted therapy; SSA, somatostatin analogue; SRS, somatostatin receptor scintigraphy.

A

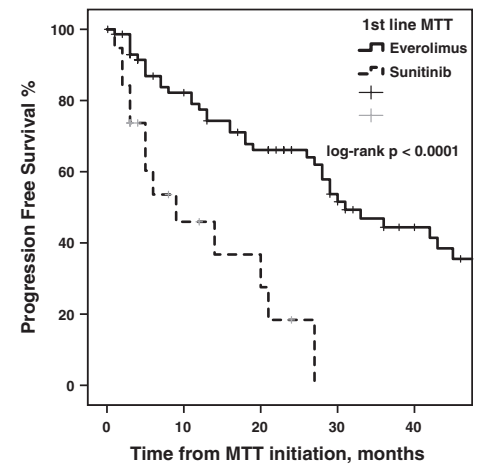

No at risk

\begin{tabular}{|l|c|c|c|c|c|}
\hline Everolimus & 73 & 53 & 40 & 25 & 16 \\
\hline Sunitinib & 19 & 6 & 4 & 0 & 0 \\
\hline
\end{tabular}

B

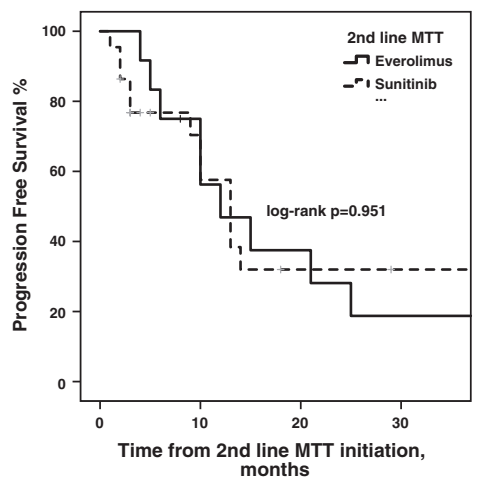

No at risk

\begin{tabular}{|l|c|c|c|c|}
\hline Everolimus & 12 & 8 & 4 & 2 \\
\hline Sunitinib & 22 & 11 & 4 & 3 \\
\hline
\end{tabular}

\section{Figure 3}

(A) Progression-free survival (PFS) to first-line molecular targeted therapy (MTT) stratified by MTTagent (everolimus vs sunitinib) with patient at risk table below. (B) Progression-free survival (PFS) to second-line molecular targeted therapy (MTT) stratified by MTT agent (everolimus vs sunitinib) with patient at risk table below. https://ec.bioscientifica.com https://doi.org/10.1530/EC-19-0134 (c) 2019 The authors Published by Bioscientifica Ltd

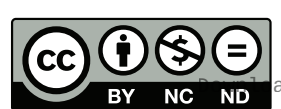

This work is licensed under a Creative Commons Attribution-NonCommercial-NoDerivatives 4.0 Internationab bicense.ifica . com at 04/26/2023 12:33:49PM 
of chemotherapy (HR: $2.71 ; 95 \% \mathrm{CI}: 1.2-6.3 ; P=0.021$ ) were demonstrated as negative independent prognostic factors for PFS under MTT (Table 3). For PanNENs $(n=57)$ in particular, median PFS under first-line MTT was 31 months (95\% CI: 24.5-37.5) in the everolimus group ( $n=42$ ) versus 9 months (95\% CI: 2.3-15.7) in the sunitinib group $(n=15)$, respectively (log-rank $P<0.0001$; Fig. 4). Cox regression analysis for PFS of first-line MTT in PanNENs confirmed that sunitinib treatment (HR: 4.9; 95\% CI: 1.8-13.9; $P=0.002$ ) and KI67 >20\% (HR: 76.3; 95\% CI: 5-1171; $P=0.002)$ were negative independent prognostic factors (Supplementary Table 4).

Log-rank OS analysis, did not exhibit any differences between patients receiving everolimus compared to sunitinib as first- and second-line MTT, respectively (logrank $P=0.510$ and log-rank $P=0.451$, respectively; Fig. 5).

MKVPCI analysis with shrinkage of investigated variables, confirmed the choice of sunitinib (HR: 1.88; 95\% CI: 1-3.5), KI67 >20\% (HR: 4.77; 95\% CI: 1.65-13.8) and prior administration of chemotherapy (HR: $2.75 ; 95 \%$
CI: $1.59-4.75)$ as predictors for progression to first-line MTT (Table 4). Additionally, in MKVPCI analysis, HR >1.5 for progression were encountered in patients with lung/ thymic NENs and higher CCI receiving first-line MTT, as well as in patients with advanced LTL at second-line MTT (risk for progression or death, Table 4).

\section{Side effects}

MTT with everolimus or sunitinib was generally well tolerated. From the entire cohort of 92 patients, 56 (61\%) experienced any SE during first- or second-line MTT, mostly grades 1 and 2 toxicities. SEs grade $>3$ were encountered in 16 patients (17.4\%). Table 5 summarizes the most common SE and the frequency of their appearance, as well as the SE grade. Fatigue, gastrointestinal symptoms (nausea, vomiting, diarrhoea, abdominal pain) and haematological complications (reduced platelet, haematocrit and white blood cell count) were the most frequent grade 1-2 SE noticed. Twenty patients treated with

Table 3 Multivariate Cox regression model for progression-free survival (PFS) for all patients receiving first-line molecular targeted therapy (MTT).

\begin{tabular}{l} 
Prognostic factor for PFS \\
\hline MTT agent \\
Everolimus \\
Sunitinib \\
Age at baseline \\
Site of primary \\
Pancreas \\
Small intestine \\
Lung/thymus \\
Unknown primary (UPO) \\
Liver tumour load \\
No liver metastases \\
$<5$ unilobar liver metastases \\
$5-10$ unilobar and/or bilobar liver metastases \\
$>10$ liver metastases or diffuse liver metastases \\
KI67 groups \\
KI67 <3\% \\
KI67 3-20\% \\
KI67 $>20 \%$ \\
SRS or ${ }^{68}$ Ga-PET \\
Negative \\
Positive \\
Unknown \\
Prior resective surgery \\
No \\
Yes \\
Prior chemotherapy \\
No \\
Yes
\end{tabular}

\begin{tabular}{c}
\hline $\mathbf{H R}$ \\
\hline 1 \\
3.47 \\
0.99
\end{tabular}

\begin{tabular}{c}
\hline $\mathbf{9 5 \%} \mathbf{~ C l}$ \\
\hline \\
\\
$1.46-8.25$ \\
$0.96-1.01$
\end{tabular}

\begin{tabular}{c}
\hline P value \\
\hline \\
\\
0.005 \\
0.285
\end{tabular}

\section{1}

0.71

1.16

$0.28-1.76$

0.453

1.81

$0.27-5.03$

0.842

1

1.98

0.95

1.51

$0.31-10.63$

0.511

1
0.751
6.38

$0.31-12.55$

0.75

0.467

$0.15-6.15 \quad 0.954$

$0.32-7.13 \quad 0.603$

Bold indicates statistical significance.

$\mathrm{Cl}$, confidence interval; Ga, Gallium; HR, hazard ratio; MEN1, multiple endocrine neoplasia type 1; MTT, molecular targeted therapy; SRS, somatostatin receptor scintigraphy.

https://ec.bioscientifica.com https://doi.org/10.1530/EC-19-0134 (c) 2019 The authors Published by Bioscientifica Ltd

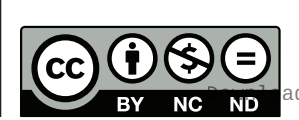

This work is licensed under a Creative Commons Attribution-NonCommercial-NoDerivatives 4.0 elnternationab bicense.ifica. com at 04/26/2023 12:33:49PM 
A

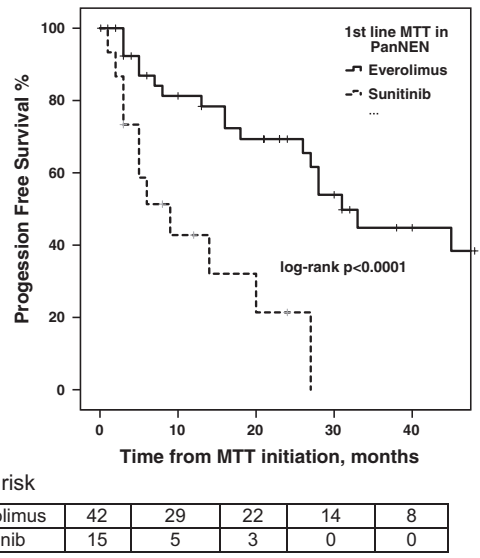

B

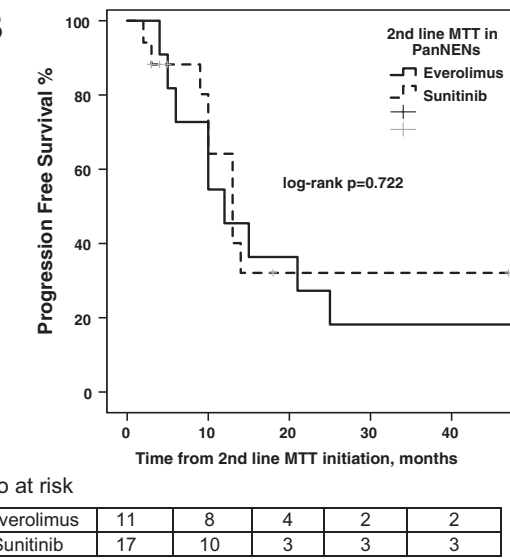

\section{Figure 4}

(A) Progression-free survival (PFS) to first-line molecular targeted therapy (MTT) in patients with pancreatic neuroendocrine neoplasms (PanNEN) stratified by MTT agent (everolimus vs sunitinib) with patient at risk table below. (B) Progressionfree survival (PFS) to second-line MTT in patients with PanNENs stratified by MTT agent (everolimus vs sunitinib) with patient at risk table below. everolimus manifested uncontrolled diabetes mellitus, whereas two patients had a new onset of hypertension while on sunitinib treatment. Of the 16 patients who developed serious toxicities (grade 3 and above), SE most commonly included bone marrow suppression, acute renal failure and/or pneumonitis leading to treatment discontinuation. Another 12 patients discontinued MTT mainly due to fatigue. All other patients who developed grades 1-2 SE were given medications for symptomatic relief and had MTT dosage reduction as per guidelines. The discontinuation rate due to SE was as high as 20/85 for everolimus versus $4 / 41$ for sunitinib $(P=0.065)$.

Among the 85 patients receiving everolimus as first$(n=73)$ or second-line MTT $(n=12)$, SE were encountered in 40 patients. Thirteen patients treated with everolimus had grade $3 \mathrm{SE}$ and above, mainly consisting of acute renal failure and pneumonitis. On the other hand, among the 41 patients receiving sunitinib as first- $(n=19)$ or secondline MTT $(n=22)$, SEs were encountered in 25 patients, with toxicity of grade 3 and above being observed in four patients.

In the subset of PanNENs ( $n=56), 24 / 41$ patients who received everolimus experienced any SE during firstline MTT, mostly grades 1 and 2 toxicities versus 10/15 in the sunitinib group ( $P$ value: 0.581 ). These figures for second-line MTT in PanNENs were $2 / 11$ versus $7 / 17$ for everolimus and sunitinib, respectively $(P=0.689)$.

Finally, there was no additive toxicity at second-line MTT neither for everolimus nor for sunitinib. In particular, comparable SE rates were encountered between patients receiving first- (37/73) and second-line everolimus (3/12; $P=0.122$ ), whereas lower SE rates were demonstrated at second- (5/22) compared to first-line sunitinib (14/19, $P=0.001$ ). Previous chemotherapy administration was not associated to additive toxicity under MTT either $(P=0.463)$.

\section{Discussion}

This study assessed the outcomes of patients with NENs receiving MTT with everolimus or sunitinib, as a firstand second-line (sequential) MTT, mainly combined with SSAs in a single-centre observational setting. A higher PFS benefit was found after uni- and multivariable analysis (HR: 3.47; 95\% CI: 1.5-8.3; $P=0.005$ ) and confirmed by multi-state modelling (HR: $1.88 ; 95 \%$ CI: 1-3.5) for patients treated with everolimus at first-line
A

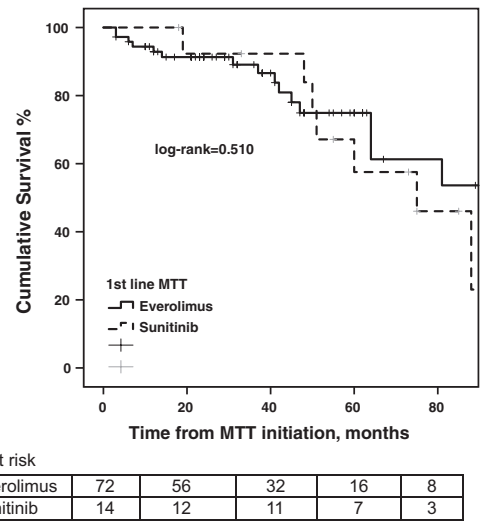

B

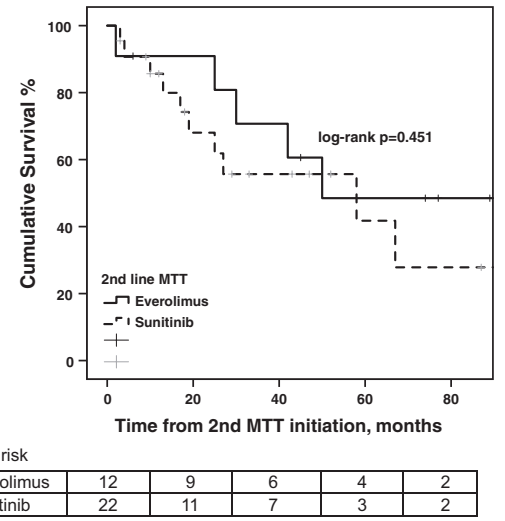

Figure 5

(A) Overall survival (OS) from molecular targeted therapy (MTT) initiation stratified by MTT agent (everolimus vs sunitinib) with patient at risk table below. (B) Overall survival (OS) from second-line MTT initiation stratified by MTT agent (everolimus vs sunitinib) with patient at risk table below. https://ec.bioscientifica.com https://doi.org/10.1530/EC-19-0134 (c) 2019 The authors Published by Bioscientifica Ltd

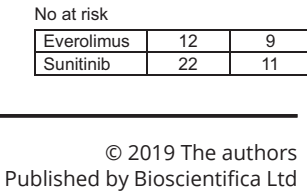

This work is licensed under a Creative Commons Attribution-NonCommercial-NoDerivatives 4.0 elnternationad ticense ifica. com at 04/26/2023 12:33:49PM 
Table 4 Results of multi-state Markov modelling of prognostic effects on progression and death.

\begin{tabular}{|c|c|c|c|c|c|}
\hline \multirow{2}{*}{ Characteristics } & & $\begin{array}{l}\text { Progression under } \\
\text { 1st line MTT }\end{array}$ & $\begin{array}{c}\text { Progression under } \\
\text { sequential 2nd line } \\
\text { MTT }\end{array}$ & $\begin{array}{c}\text { Death, 1st line } \\
\text { MTT }\end{array}$ & \multirow{2}{*}{$\begin{array}{c}\begin{array}{c}\text { Death, 2nd line } \\
\text { MTT }\end{array} \\
H R(95 \% \mathrm{Cl}) \\
\end{array}$} \\
\hline & & $\begin{array}{c}\mathrm{HR}(95 \% \mathrm{Cl}) \\
\end{array}$ & $\begin{array}{c}\mathrm{HR}(95 \% \mathrm{Cl}) \\
\end{array}$ & $\mathrm{HR}(95 \% \mathrm{Cl})$ & \\
\hline \multicolumn{6}{|c|}{ Total number of patients $(n=92)$} \\
\hline \multirow[t]{2}{*}{ MTT } & Everolimus & 1 & 1 & 1 & 1 \\
\hline & Sunitinib & $1.88(1.00-3.52)$ & $1.02(0.43-2.41)$ & $1.26(0.27-5.89)$ & $1.96(0.55-6.98)$ \\
\hline \multirow[t]{2}{*}{ Gender } & Male & 1 & 1 & 1 & 1 \\
\hline & Female & $0.98(0.58-1.67)$ & $0.46(0.18-1.18)$ & $0.93(0.30-2.86)$ & $0.24(0.05-1.06)$ \\
\hline Age & Per 10 years & $0.94(0.77-1.15)$ & $0.66(0.50-0.89)$ & $1.00(0.65-1.55)$ & $0.66(0.46-0.95)$ \\
\hline \multirow[t]{2}{*}{ Inheritance } & Sporadic & $0.88(0.38-2.06)$ & $1.01(0.33-3.02)$ & $1.17(0.15-9.03)$ & $0.78(0.21-2.90)$ \\
\hline & Familial (MEN1) & 1 & 1 & 1 & 1 \\
\hline \multirow[t]{4}{*}{ Primary tumour site } & Pancreas & 1 & 1 & 1 & 1 \\
\hline & Small intestinal & $0.71(0.37-1.35)$ & $0.38(0.05-2.87)$ & $1.38(0.43-4.42)$ & N/A \\
\hline & Lung/thymus & $1.90(0.79-4.57)$ & $1.36(0.31-5.92)$ & $1.47(0.17-12.51)$ & $1.13(0.15-8.70)$ \\
\hline & Unknown primary (UPO) & $0.80(0.24-2.62)$ & $\mathrm{N} / \mathrm{A}$ & $\mathrm{N} / \mathrm{A}$ & N/A \\
\hline \multirow[t]{5}{*}{ Liver Tumour load } & No liver metastases & 1 & 1 & 1 & 1 \\
\hline & $<5$ unilobar liver metastases & $0.75(0.27-2.08)$ & $0.18(0.02-1.69)$ & $1.12(0.07-18.3)$ & $0.07(0.01-0.92)$ \\
\hline & 5-10 unilobar liver & $0.48(0.14-1.64)$ & $5.83(0.22-157)$ & $1.12(0.07-18.0)$ & $5.26(0.20-141)$ \\
\hline & $\begin{array}{l}\text { metastases and/or bilobar } \\
\text { liver metastases }\end{array}$ & $0.70(0.31-1.56)$ & $0.14(0.02-1.27)$ & $1.59(0.20-12.4)$ & $6.38(0.02-1.42)$ \\
\hline & $\begin{array}{l}\text { >10 liver metastases or } \\
\text { diffuse liver metastases }\end{array}$ & & & & \\
\hline \multirow{3}{*}{$\begin{array}{l}\text { KI67 at MTT } \\
\text { initiation }\end{array}$} & $\mathrm{KI} 67<3 \%$ & 1 & 1 & 1 & 1 \\
\hline & KI67 3-20\% & $1.00(0.50-2.02)$ & $0.98(0.29-3.35)$ & $0.32(0.08-1.21)$ & $0.99(0.22-4.45)$ \\
\hline & $\mathrm{KI} 67>20 \%$ & $4.77(1.65-13.8)$ & N/A & $8.07(1.63-39.9)$ & N/A \\
\hline \multirow[t]{2}{*}{ Secretory status } & Yes & $0.88(0.51-1.50)$ & $0.88(0.36-2.19)$ & $0.64(0.21-1.92)$ & $0.59(0.21-1.71)$ \\
\hline & No & 1 & 1 & 1 & 1 \\
\hline \multirow[t]{2}{*}{ Prior surgery } & Yes & $0.77(0.46-1.31)$ & $0.68(0.27-1.70)$ & $0.84(0.27-2.70)$ & $0.36(0.12-1.04)$ \\
\hline & No & 1 & 1 & 1 & 1 \\
\hline \multirow[t]{2}{*}{ SRS or ${ }^{68} \mathrm{Ga}$-PET } & Positive & $0.92(0.48-1.78)$ & $0.52(0.19-1.43)$ & $0.36(0.11-1.20)$ & $2.16(0.28-16.6)$ \\
\hline & Negative/unknown & 1 & 1 & 1 & 1 \\
\hline \multirow[t]{2}{*}{ FDG-PET } & Positive & $1.04(0.74-1.48)$ & $0.86(0.50-1.48)$ & $1.13(0.50-2.54)$ & $0.99(0.48-2.02)$ \\
\hline & Negative & 1 & 1 & 1 & 1 \\
\hline \multirow[t]{2}{*}{ Previous treatments } & SSA or naive & 1 & 1 & 1 & 1 \\
\hline & $\begin{array}{l}\text { Pre-treated with } \\
\text { chemotherapy }\end{array}$ & $2.75(1.59-4.75)$ & $0.38(0.05-2.98)$ & $2.38(0.70-8.10)$ & $0.29(0.04-2.36)$ \\
\hline \multirow[t]{4}{*}{$\mathrm{CCl}$} & 0 & 1 & 1 & 1 & 1 \\
\hline & 1 & $0.65(0.33-1.28)$ & $0.95(0.31-2.95)$ & $0.80(0.21-2.98)$ & $2.81(0.94-8.43)$ \\
\hline & 2 & $1.53(0.60-3.91)$ & $0.88(0.12-6.68)$ & $1.19(0.15-9.54)$ & N/A \\
\hline & 3 & $\mathrm{~N} / \mathrm{A}$ & $\mathrm{N} / \mathrm{A}$ & $\mathrm{N} / \mathrm{A}$ & $\mathrm{N} / \mathrm{A}$ \\
\hline
\end{tabular}

CCI, Charlson Comorbidity Index; Cl, confidence interval; FDG-PET, fluoro-deoxyglucose positron emission tomography; Ga, Gallium; HR, hazard ratio; MEN1, multiple endocrine neoplasia type 1; MTT, molecular targeted therapy; SRS, somatostatin receptor scintigraphy; SSA, somatostatin analogue.

MTT irrespective of the tissue of origin. Overall, DCR was higher in all patients treated with everolimus vs sunitinib ( 88 vs $63 \%, P=0.012$ ), whereas a similar trend was noted for the PanNEN group (86\% with everolimus versus $60 \%$ with sunitinib $(P=0.062)$ ). In addition, prior administration of chemotherapy (HR: 2.75; 95\% CI: 1.59-4.75) and a KI67 proliferation index $>20 \%$ (HR: 4.77; 95\% CI: 1.65-13.8) were identified as predictors for progression or death under first-line MTT. However, no difference in OS between the two groups (everolimus versus sunitinib, first- and secondline) was observed. Comparable safety profiles were evident with both agents; serious toxicities were in the range of $10-15 \%$, and the discontinuation rate due to (c) 2019 The authors Published by Bioscientifica Ltd
SE was as high as 20/85 for everolimus versus $4 / 41$ for sunitinib $(P=0.065)$. Foremost, no additive toxicities at sequential MTT application were encountered in this series.

Generally, dose escalation or an increase in frequency of SSAs may be considered in G1-2 NEN patients with KI67 $\mathrm{LI}<10 \%$ and $\mathrm{PD}$, being previously treated with a standard SSA dose $(23,24)$. Robust evidence based on phase III RCTs has established the role of MTT with either everolimus or sunitinib in progressive WD G1 and G2 PanNENs (2, 3). In PanNENs, MTT can be first- or second-line therapy, subsequent to SSAs or chemotherapy, respectively $(12,9)$. However, there are few head-to-head comparisons of the anti-tumour activity and safety profile of MTT in NEN.

This work is licensed under a Creative Commons Attribution-NonCommercial-NoDerivatives 4.0 International License.ifica com at $04 / 26 / 2023$ 12:33:49PM 
Table 5 Adverse effects.

\begin{tabular}{|c|c|c|c|c|c|c|c|c|}
\hline \multirow[b]{3}{*}{ Side effects } & \multicolumn{8}{|c|}{ Maximum toxicity grade } \\
\hline & \multicolumn{2}{|c|}{ 1st line everolimus } & \multicolumn{2}{|c|}{ 1st line sunitinib } & \multicolumn{2}{|c|}{ 2nd line everolimus } & \multicolumn{2}{|c|}{ 2nd line sunitinib } \\
\hline & Grade 1 and 2 & Grade 3 & Grade 1 and 2 & Grade 3 & Grade 1 and 2 & Grade 3 & Grade 1 and 2 & Grade 3 \\
\hline Haematological & 7 & 1 & 1 & 0 & 1 & 1 & 0 & 0 \\
\hline $\begin{array}{l}\text { Gastrointestinal } \\
\text { intolerance }\end{array}$ & 6 & 0 & 3 & 0 & 1 & 0 & 4 & 0 \\
\hline Pneumonitis & 0 & 4 & 0 & 1 & & & & \\
\hline Hepatotoxicity & 2 & 0 & 0 & 0 & 0 & 0 & 0 & 0 \\
\hline Nephrotoxicity & 1 & 6 & 0 & 0 & 0 & 0 & 1 & 0 \\
\hline Mucocutaneous & & & & & & & & \\
\hline Dermatitis & 4 & 0 & 2 & 0 & 1 & 0 & 1 & 0 \\
\hline Stomatitis & 7 & 0 & 1 & 0 & 1 & 0 & 1 & 0 \\
\hline $\begin{array}{l}\text { Palmar-plantar } \\
\text { syndrome }\end{array}$ & 1 & 0 & 0 & 0 & 0 & 0 & 0 & 0 \\
\hline Fatigue & 8 & 2 & 5 & 2 & 0 & 0 & 3 & 1 \\
\hline Diabetes mellitus & 15 & 1 & 0 & 0 & 4 & 0 & 0 & 0 \\
\hline Hypertension & 0 & 0 & 1 & 0 & 0 & 0 & 1 & 0 \\
\hline
\end{tabular}

Hence, to date, selection of either everolimus or sunitinib has been made based on local regimen availability and preferences, as well as the patient's anticipated SE profiles. Integration of other available modalities, such as peptide receptor radionuclide therapy (PRRT), may also be considered according to the availability of this treatment modality. For the small intestinal and bronchial primaries, recent randomized trials also favour the use of everolimus $(10,6)$. However, the results of RADIANT- 4 trial were not available at MTT initiation for the few patients $(n=4)$ with non-pancreatic NENs who received sequential MTT with first-line sunitinib in our study (6). Importantly, higher DCR and prolonged PFS were encountered in our study in all NEN patients treated with first-line everolimus. Of particular interest in PanNENs $(n=57)$, DCR with everolimus achieved marginal statistical significance $(P=0.062)$ in comparison with sunitinib, but still a PFS benefit was clearly evident in these patients in crude and multivariable analyses. Although sunitinib is not currently licensed for NENs of non-pancreatic origin, primary tumour site was not demonstrated as an independent predictor of PFS at first- and second-line MTT in multivariable Cox regression analysis. Additionally, the rationale of the present study in terms of the included patient population is also in accordance with presently ongoing, phase I, II and III clinical trials that investigate a wide range of emerging RTK inhibitors in the treatment of progressive NENs from various tissues of origin (25).

Currently, MTT selection and sequencing for NEN management is not relying on molecularly tailored choices due to a lack of biomarkers to predict and monitor treatment response in NEN patients. Preclinical studies have demonstrated that aberrations of PI3KCA and PTEN and elevated PAKT in the MTOR pathway may predict ex vivo sensitivity to rapalogues (26). A recent study demonstrated that over-activation of GSK3 may be a potential marker of everolimus resistance in PanNEN cell lines (27). Additionally, somatic mutations linked with the MTOR pathway are encountered in 15\% of PanNENs (28). Regarding MTT with RTK inhibitors, SVEGFR-3, IL8 and SDF-1A were recently identified as predictors of response to sunitinib in a phase II trial (29). However, validation of clinical trials and incorporation of these results in the clinical setting are largely missing.

Direct comparison of MTTs with respect to their benefits and risks is currently incomplete. Therefore, to date, there are no reference standards supporting the use of one over the other. Everolimus has been approved as first-line therapy in all NENs, whereas sunitinib has been approved for PanNENs only. With respect to PanNENs, no randomized clinical trial has provided a head-to-head comparison regarding efficacy and safety. Moreover, published comparative studies of retrospective real-world data are scarce (13). A recent network meta-analysis comparing DCR for different NEN therapies from all available RCTs demonstrated that single therapy with everolimus and combination therapies were most effective (30). Specifically, everolimus alone or in combination with SSA or interferon achieved the highest DCR, followed by single treatment with SSA, interferon, sunitinib and placebo (30). These results are in accordance with the findings of our study, where using real-world data, everolimus alone or more commonly in combination with SSAs was associated with longer PFS at first-line MTT compared to sunitinib. Apart from traditional uni- and multivariable analyses, our study also applied modern statistical methods to control biases inherent in cohort studies, which confirmed that 
everolimus may be preferable to sunitinib when initiating MTT in progressive NENs (HR: 1.88 for progression at first-line MTT). Additionally, prior administration of chemotherapy (HR: 2.75) and KI67 >20\% (HR: 4.77) were identified as predictors for progression to first-line MTT. Finally, the findings of the present study may also guide future research by elucidating the role of different MTT agents and that of predictive clinicopathological markers in NEN management with MTTs, thus facilitating appropriate trial design.

In the subset of PanNENs, the reasons for longer PFS (31 months) in everolimus-treated patients in our study compared to the corresponding figure (11 months) reported in RADIANT-3 trial could have been multifactorial (31). RADIANT-3 trial reports a median follow-up period of 17 months and a median duration of treatment with everolimus 8.79 months (range, 0.25-27.47), as compared with median duration of 21 months (range 1-89) in our study. Additionally, only $31 \%$ of the patients in the everolimus group in RADIANT-3 were administered treatment for a minimum of 12 months, as compared with $51 / 73$ in patients treated with first-line everolimus in our study. Finally, previous chemotherapy administration was as high as 50\% in the RADIANT-3 trial, as compared to only $17 / 73$ in the everolimus group in our study. Importantly, prior chemotherapy administration was demonstrated to be a negative independent prognostic factor of PFS and a predictor of resistance to MTT in our study.

Generally, in hypervascularized WD NENs, morphological changes that are clearly observed after exposure to MTTs such as everolimus, and most importantly to anti-angiogenic drugs, e.g. sunitinib, may be poorly assessed by the currently applied RECIST criteria, which apparently reflect tumour shrinkage or progression in size. Several trials have challenged the validity of traditional RECIST dimension criteria to assess the anti-tumoural effects of MTT, and have proposed incorporating the evaluation of changes in tumour density using contrast enhanced computed tomography, dynamic contrast magnetic resonance imaging or highfrequency Doppler ultrasonography $(32,33)$. Taking into consideration the aforementioned limitations of RECIST criteria, we assessed DCR rather than objective responses in order to evaluate the effects of MTT, as PR at first$(n=8)$ and second-line MTT $(n=1)$ were indeed only few in our cohort and mainly observed in patients receiving everolimus ( $n=8$ ). Additionally, SSAs that were commonly used in combination with MTT in the present study have stabilizing rather than shrinkage effects in NENs $(34,35)$; thus, DCR assessment seems more reasonable in this setting.
Importantly, the seminal randomized controlled trials that resulted in MTT monotherapy approval for NENs in clinical practice do not report neither OR nor SD rates (2, $6,3)$; and no studies are currently available reporting DCR of MTT combined with SSAs.

In the present study, the safety profile of everolimus (as single agent or combined with SSAs) was similar to prior reports of everolimus monotherapy and a recent phase II trial on everolimus and octreotide LAR combination in gastroenteropancreatic NENs (EVERLAR trial), suggesting that prompt management of everolimus SE may reduce the potential toxicity of its combination with SSAs (36, $10,6)$. To date, reports on the safety profile of sunitinib combined with SSAs analogues in NEN treatment are lacking. Our study confirmed a SE rate of sunitinib, mainly combined with SSAs in accordance with the seminal study by Raymond et al. on sunitinib monotherapy in PanNENs that reported approximately $30 \%$ SE rate and grade 3 or 4 toxicity in the range of $10-12 \%$ (2). Additionally, we report a lack of additive toxicity related to sequential MTT in NEN management. Importantly, our findings on MTT safety profile should be interpreted in the light of our study design as the duration of MTT was often prolonged, that is, until disease progression or serious toxicity occurred and the MTT administration was sequential in a subset of patients. However, the retrospective nature of our study and the lack of quantifiable information with appropriate quality of life questionnaires while on MTT, limits indeed our ability to accurately determine the safety profile of MTT agents investigated here.

Our study has several limitations, the most important limitation being in its retrospective nature. This may explain the allocation of a different number of patients in each MTT group and differences in duration of treatment. Additionally, NEN heterogeneity plus the inclusion of NENs originating both from the pancreas and the small intestine, as well as that of NENs of thoracic and unknown origin, may have confounded the results. However, considering the distinct characteristics of PanNENs and those of other NENs, our efficacy analysis for the PanNEN subset was performed separately. Finally, the fact that the patient population in our study only includes referrals to a tertiary centre may include a certain referral bias. Importantly, the MKVPCI model and the extension of shrinkage methods to bias modelling applied in the present study allowed us to check for variables that were known or presumed confounders, as well as for sources of uncertainty, selection bias, misclassification and unmeasured confounders, thus adding to the validity of the study results (21). The main strengths of this study

This work is licensed under a Creative Commons Attribution-NonCommercial-NoDerivatives 4.0 Internationab ticense.ifica. com at $04 / 26 / 2023$ 12:33:49PM 
are the central assessment of responses according to RECIST criteria and making use of centralized pathology by dedicated radiologists and pathologists involved in the institutional multidisciplinary tumour board.

In conclusion, our comparison of real-world data in patients treated with MTT suggests that, between the two currently approved targeted agents for NEN treatment, the MTOR inhibitor everolimus may be preferable to the RTK inhibitor sunitinib in terms of its anti-tumour activity at first-line MTT; this may have important implications for MTT selection and sequencing in clinical practice. Comparable safety profiles and no additive toxicities at sequential MTT application were encountered with both agents. Despite the sophisticated statistical methodology of this study, it is clear that a prospective, randomized, controlled trial will further clarify the value of MTT in NENs with respect to treatment selection and sequencing. Importantly, as no ideal predictive markers for MTT are available to date, one of the most important future tasks is to incorporate the validation of such markers in adequately designed MTT trials.

\section{Supplementary data}

This is linked to the online version of the paper at https://doi.org/10.1530/ EC-19-0134.

\section{Declaration of interest}

The authors declare that there is no conflict of interest that could be perceived as prejudicing the impartiality of the research reported.

\section{Funding}

K Daskalakis was supported by the Swedish Society of Medicine Post Doctoral Scholarhip and the Lennanders fund.

\section{Author contribution statement}

G Kaltsas and A Koumarianou contributed equally.

\section{References}

1 Dasari A, Shen C, Halperin D, Zhao B, Zhou S, Xu Y, Shih T \& Yao JC. Trends in the incidence, prevalence, and survival outcomes in patients with neuroendocrine tumors in the United States. JAMA Oncology 20173 1335-1342. (https://doi.org/10.1001/ jamaoncol.2017.0589)

2 Raymond E, Dahan L, Raoul JL, Bang YJ, Borbath I, LombardBohas C, Valle J, Metrakos P, Smith D, Vinik A, et al. Sunitinib malate for the treatment of pancreatic neuroendocrine tumors. New England Journal of Medicine 2011364 501-513. (https://doi.org/10.1056/ NEJMoa1003825)

3 Yao JC, Pavel M, Lombard-Bohas C, Van Cutsem E, Voi M, Brandt U, He W, Chen D, Capdevila J, de Vries EGE, et al. Everolimus for the treatment of advanced pancreatic neuroendocrine tumors: overall survival and circulating biomarkers from the randomized, phase III RADIANT-3 study. Journal of Clinical Oncology 201634 3906-3913. (https://doi.org/10.1200/JCO.2016.68.0702)

4 Phan AT, Halperin DM, Chan JA, Fogelman DR, Hess KR, Malinowski P, Regan E, Ng CS, Yao JC \& Kulke MH. Pazopanib and depot octreotide in advanced, well-differentiated neuroendocrine tumours: a multicentre, single-group, phase 2 study. Lancet: Oncology 201516 695-703. (https://doi.org/10.1016/S14702045(15)70136-1)

5 Strosberg JR, Cives M, Hwang J, Weber T, Nickerson M, Atreya CE, Venook A, Kelley RK, Valone T, Morse B, et al. A phase II study of axitinib in advanced neuroendocrine tumors. Endocrine-Related Cancer 201623 411-418. (https://doi.org/10.1530/ERC-16-0008)

6 Yao JC, Fazio N, Singh S, Buzzoni R, Carnaghi C, Wolin E, Tomasek J, Raderer M, Lahner H, Voi M, et al. Everolimus for the treatment of advanced, non-functional neuroendocrine tumours of the lung or gastrointestinal tract (RADIANT-4): a randomised, placebocontrolled, phase 3 study. Lancet 2016387 968-977. (https://doi. org/10.1016/S0140-6736(15)00817-X)

7 Capdevila J, Casanovas O, Salazar R, Castellano D, Segura A, Fuster P, Aller J, Garcia-Carbonero R, Jimenez-Fonseca P, Grande E, et al. Translational research in neuroendocrine tumors: pitfalls and opportunities. Oncogene 201736 1899-1907. (https://doi. org/10.1038/onc.2016.316)

8 Qian ZR, Ter-Minassian M, Chan JA, Imamura Y, Hooshmand SM, Kuchiba A, Morikawa T, Brais LK, Daskalova A, Heafield R, et al. Prognostic significance of MTOR pathway component expression in neuroendocrine tumors. Journal of Clinical Oncology 201331 3418-3425. (https://doi.org/10.1200/JCO.2012.46.6946)

9 Lombard-Bohas C, Yao JC, Hobday T, Van Cutsem E, Wolin EM, Panneerselvam A, Stergiopoulos S, Shah MH, Capdevila J \& Pommier R. Impact of prior chemotherapy use on the efficacy of everolimus in patients with advanced pancreatic neuroendocrine tumors: a subgroup analysis of the phase III RADIANT-3 trial. Pancreas 201544 181-189. (https://doi.org/10.1097/ MPA.0000000000000262)

10 Pavel ME, Hainsworth JD, Baudin E, Peeters M, Horsch D, Winkler RE, Klimovsky J, Lebwohl D, Jehl V, Wolin EM, et al. Everolimus plus octreotide long-acting repeatable for the treatment of advanced neuroendocrine tumours associated with carcinoid syndrome (RADIANT-2): a randomised, placebo-controlled, phase 3 study. Lancet 2011378 2005-2012. (https://doi.org/10.1016/S01406736(11)61742-X)

11 Terris B, Scoazec JY, Rubbia L, Bregeaud L, Pepper MS, Ruszniewski P, Belghiti J, Flejou J \& Degott C. Expression of vascular endothelial growth factor in digestive neuroendocrine tumours. Histopathology 199832 133-138. (https://doi.org/10.1046/j.13652559.1998.00321.x)

12 Angelousi A, Kamp K, Kaltsatou M, O'Toole D, Kaltsas G \& de Herder W. Sequential everolimus and sunitinib treatment in pancreatic metastatic well-differentiated neuroendocrine tumours resistant to prior treatments. Neuroendocrinology 2017105 394-402. (https://doi.org/10.1159/000456035)

13 Yoo C, Cho H, Song MJ, Hong SM, Kim KP, Chang HM, Chae H, Kim TW, Hong YS, Ryu MH, et al. Efficacy and safety of everolimus and sunitinib in patients with gastroenteropancreatic neuroendocrine tumor. Cancer Chemotherapy and Pharmacology 2017 79 139-146. (https://doi.org/10.1007/s00280-016-3215-3)

14 Eisenhauer EA, Therasse P, Bogaerts J, Schwartz LH, Sargent D, Ford R, Dancey J, Arbuck S, Gwyther S, Mooney M, et al. New response evaluation criteria in solid tumours: revised RECIST guideline (version 1.1). European Journal of Cancer 200945 228-247. (https://doi.org/10.1016/j.ejca.2008.10.026)

15 Gress D, Greene F, Washington M, Asare E \& Brierley J. Principles of cancer staging. In AJCC Cancer Staging Manual, 8th ed. New York, NY, USA: Springer, 2017 
16 Lloyd RV, Osamura RY, Klöppel G \& Rosai J. WHO Classification of Tumours of Endocrine Organs. Lyon, France: IARC Press, 2017.

17 Charlson ME, Pompei P, Ales KL \& MacKenzie CR. A new method of classifying prognostic comorbidity in longitudinal studies: development and validation. Journal of Chronic Diseases $1987 \mathbf{4 0}$ 373-383. (https://doi.org/10.1016/0021-9681(87)90171-8)

18 National Cancer Institute. Common terminology criteria for adverse events (CTAE) v5.0 (CTCAE). Bethesda, MD, USA: Cancer Therapy Evaluation Program, 2017. (available at: https://ctep.cancer.gov/ protocolDevelopment/electronic_applications/docs/CTCAE_v5_ Quick_Reference_8.5x11.pdf)

19 von Elm E, Altman DG, Egger M, Pocock SJ, Gotzsche PC, Vandenbroucke JP \& STROBE Initiative. The Strengthening the Reporting of Observational Studies in Epidemiology (STROBE) statement: guidelines for reporting observational studies. Journal of Clinical Epidemiology 200861 344-349. (https://doi.org/10.1016/j. jclinepi.2007.11.008)

20 Alioum A \& Commenges D. MKVPCI: a computer program for Markov models with piecewise constant intensities and covariates. Computer Methods and Programs in Biomedicine 200164 109-119. (https://doi.org/10.1016/S0169-2607(00)00094-8)

21 Dancourt V, Quantin C, Abrahamowicz M, Binquet C, Alioum A $\&$ Faivre J. Modeling recurrence in colorectal cancer. Journal of Clinical Epidemiology 200457 243-251. (https://doi.org/10.1016/j. jclinepi.2003.07.012)

22 Greenland S. Invited commentary: variable selection versus shrinkage in the control of multiple confounders. American Journal of Epidemiology 2008167 523-529; discussion 530-521. (https://doi. org/10.1093/aje/kwm355)

23 Strosberg JR, Benson AB, Huynh L, Duh MS, Goldman J, Sahai V, Rademaker AW \& Kulke MH. Clinical benefits of above-standard dose of octreotide LAR in patients with neuroendocrine tumors for control of carcinoid syndrome symptoms: a multicenter retrospective chart review study. Oncologist 201419 930-936. (https://doi.org/10.1634/ theoncologist.2014-0120)

24 Yao JC, Chan JA, Mita AC, Kundu MG, Hermosillo Resendiz K, Hu K, Ravichandran S, Strosberg JR \& Wolin EM. Phase I dose-escalation study of long-acting pasireotide in patients with neuroendocrine tumors. OncoTargets and Therapy $2017103177-3186$. (https://doi. org/10.2147/OTT.S128547)

25 Grillo F, Florio T, Ferrau F, Kara E, Fanciulli G, Faggiano A, Colao A \& NIKE Group. Emerging multitarget tyrosine kinase inhibitors in the treatment of neuroendocrine neoplasms. Endocrine-Related Cancer 201825 R453-R466. (https://doi.org/10.1530/ERC-17-0531)

26 Meric-Bernstam F, Akcakanat A, Chen H, Do KA, Sangai T, Adkins F, Gonzalez-Angulo AM, Rashid A, Crosby K, Dong M, et al. PIK3CA/ PTEN mutations and Akt activation as markers of sensitivity to allosteric mTOR inhibitors. Clinical Cancer Research $2012 \mathbf{1 8}$ 1777-1789. (https://doi.org/10.1158/1078-0432.CCR-11-2123)

27 Aristizabal Prada ET, Spottl G, Maurer J, Lauseker M, Koziolek EJ, Schrader J, Grossman A, Pacak K, Beuschlein F, Auernhammer CJ, et al. The role of GSK3 and its reversal with GSK3 antagonism in everolimus resistance. Endocrine-Related Cancer 201825 893-908. (https://doi.org/10.1530/ERC-18-0159)

28 Scarpa A, Chang DK, Nones K, Corbo V, Patch AM, Bailey P, Lawlor RT, Johns AL, Miller DK, Mafficini A, et al. Whole-genome landscape of pancreatic neuroendocrine tumours. Nature 2017543 65-71. (https://doi.org/10.1038/nature21063)

29 Zurita AJ, Khajavi M, Wu HK, Tye L, Huang X, Kulke MH, Lenz HJ, Meropol NJ, Carley W, DePrimo SE, et al. Circulating cytokines and monocyte subpopulations as biomarkers of outcome and biological activity in sunitinib-treated patients with advanced neuroendocrine tumours. British Journal of Cancer 2015112 1199-1205. (https://doi. org/10.1038/bjc.2015.73)

30 Kaderli RM, Spanjol M, Kollar A, Butikofer L, Gloy V, Dumont RA, Seiler CA, Christ ER, Radojewski P, Briel M, et al. Therapeutic options for neuroendocrine tumors: a systematic review and network metaanalysis. JAMA Oncology 20195 480-489. (https://doi.org/10.1001/ jamaoncol.2018.6720)

31 Yao JC, Shah MH, Ito T, Bohas CL, Wolin EM, Van Cutsem E, Hobday TJ, Okusaka T, Capdevila J, de Vries EG, et al. Everolimus for advanced pancreatic neuroendocrine tumors. New England Journal of Medicine 2011364 514-523. (https://doi.org/10.1056/ NEJMoa1009290)

32 Desar IM, van Herpen CM, van Laarhoven HW, Barentsz JO, Oyen WJ \& van der Graaf WT. Beyond RECIST: molecular and functional imaging techniques for evaluation of response to targeted therapy. Cancer Treatment Reviews 200935 309-321. (https://doi. org/10.1016/j.ctrv.2008.12.001)

33 Faivre S, Zappa M, Vilgrain V, Boucher E, Douillard JY, Lim HY, Kim JS, Im SA, Kang YK, Bouattour M, et al. Changes in tumor density in patients with advanced hepatocellular carcinoma treated with sunitinib. Clinical Cancer Research 201117 4504-4512. (https:// doi.org/10.1158/1078-0432.CCR-10-1708)

34 Caplin ME, Pavel M, Cwikla JB, Phan AT, Raderer M, Sedlackova E, Cadiot G, Wolin EM, Capdevila J, Wall L, et al. Lanreotide in metastatic enteropancreatic neuroendocrine tumors. New England Journal of Medicine 2014371 224-233. (https://doi.org/10.1056/ NEJMoa1316158)

35 Rinke A, Muller HH, Schade-Brittinger C, Klose KJ, Barth P, Wied M, Mayer C, Aminossadati B, Pape UF, Blaker M, et al. Placebocontrolled, double-blind, prospective, randomized study on the effect of octreotide LAR in the control of tumor growth in patients with metastatic neuroendocrine midgut tumors: a report from the PROMID Study Group. Journal of Clinical Oncology 200927 4656-4663. (https://doi.org/10.1200/JCO.2009.22.8510)

36 Capdevila J, Teule A, Barriuso J, Castellano D, Lopez C, Manzano JL, Alonso V, Garcia-Carbonero R, Dotor E, Matos I, et al. Phase II study of everolimus and octreotide LAR in patients with nonfunctioning gastrointestinal neuroendocrine tumors: the GETNE1003_EVERLAR study. Oncologist 201924 38-46. (https://doi.org/10.1634/ theoncologist.2017-0622)

Received in final form 17 April 2019

Accepted 24 April 2019

Accepted Preprint published online 26 April 2019 https://ec.bioscientifica.com https://doi.org/10.1530/EC-19-0134 (c) 2019 The authors Published by Bioscientifica Ltd
This work is licensed under a Creative Commons Attribution-NonCommercial-NoDerivatives 4.0 Internationab ticense.ifica com at $04 / 26 / 2023 \quad 12: 33: 49 \mathrm{PM}$ 